\title{
FORMULASI SEDIAAN GEL ANTISEPTIK DAUN SIRIH HIJAU (Piper betle linn) DENGAN BASIS BIJI RAMI (Linum usitatissimum) DAN PENAMBAHAN SARI JERUK NIPIS (Citrus $x$ aurantiifolia) SEBAGAI AROMA
}

\author{
Zalzabila Lusyana $^{1 *}$, Susi Andriani ${ }^{2}$, Elih Sutisna Yanto ${ }^{3}$ \\ ${ }^{1}$ Sekolah Tinggi Ilmu Kesehatan Holistik \\ *Korespondensi: Jl.Veteran No. 272 Ciseureuh Purwakarta, Email : zalzabilalusyana@gmail.com
}

\begin{abstract}
ABSTRAK
Latar Belakang: Sirih hijau mempunyai kelebihan daya antiseptik yang lebih dominan dibanding sirih lain, karena daya antiseptiknya yang kuat sering dimanfaatkan secara empiris untuk mengobati berbagai penyakit. Berkembangnya keinginan masyarakat untuk menggunakan bahan alam atau "back to nature", ditanggapi dengan banyak produk-produk topikal berbahan aktif tanaman untuk perawatan kesehatan, kosmetik dan pencegahan penyakit. Piper batle Linn atau sirih hijau merupakan salah satu tanaman yang diketahui berkhasiat sebagai antiseptik. Penggunaan sirih hijau secara tradisional biasanya dengan merebus daun sirih kemudian air rebusan digunakan untuk kumur dan membersihkan bagian tubuh lain, atau daun sirih dilumatkan kemudian ditempelkan pada luka (Lindawaty, 2009).

Tujuan Penelitian: Penelitian ini bertujuan untuk membuat formulasi gel antiseptik yang berbasis biji rami dan ditambahkan dengan sari buah jeruk nipis sebagai aromatik, membuat gel antiseptik yang stabil dan homogen serta mengetahui $\mathrm{pH}$ yang di uji pada suhu ruang dan memiliki bentuk, warna, dan bau yang baik.

Metode: Penelitian ini menggunakan desain penelitian tindakan (action research) desain penelitian tindakan ini bertujuan untuk mengidentifikasi dan menemukan solusi dari sebuah masalah yang diteliti. Pada penelitian ini menggunakan 4 siklus antara komponen penting, seperti perencanaan, tindakan, pengamatan, dan refleksi. Perencanaan penelitian ini berupa tahapan-tahapan perencanaan kerja yang harus dilakukan pada saat penelitian, lalu dilanjutkan dengan penelitian dan pengamatan hasil dari penelitian kemudian dianalisis sebagai refleksi terhadap ketercapaian peneliti pada saat penelitian.

Hasil: Hasil susut pengeringan dari simplisia yg digunakan yaitu daun sirih sebesar 73,4 \% berdasarkan uji stabilitas $\mathrm{pH}$ mengalami kenaikan pada sediaan, sediaan homogen, dan bertahan selama 20 hari.

Simpulan: Simpulan dari penelitian ini yaitu stabilitas fisik sediaan formula II dan III dapat bertahan selama 20 hari pada penyimpanan suhu kamar $\left(15-30^{\circ} \mathrm{C}\right)$ dengan $\mathrm{pH}$ awal 4 dan pH akhir 6, kuning kecoklatan, bau khas jeruk nipis dan sirih, tekstur licin. Pada suhu dingin $\left( \pm 4^{\circ} \mathrm{C}\right)$, formula II dan III dapat bertahan selama 21 hari.
\end{abstract}

Kata kunci: Daun sirih, gel biji rami, sari jeruk nipis, gel antiseptik.

\begin{abstract}
Background: Green betel has an excess of antiseptic power which is more dominant than other betel, because its strong antiseptic power is often used empirically to treat various diseases. The growing public desire to use natural ingredients or "back to nature" has been responded by many topical products with active plant ingredients for health care, cosmetics and disease prevention. Piper batle Linn or green betel is one of the plants known to have antiseptic properties. The traditional use of green betel is usually by boiling betel leaves then boiled water is used to rinse and clean other parts of the body, or crushed betel leaf and then attached to the wound (Lindawaty, 2009).
\end{abstract}


Objective: This study aims to make an antiseptic gel formulation based on flaxseed and added with lime juice as an aromatic, to make a stable and homogeneous antiseptic gel and to determine the $\mathrm{pH}$ that was tested at room temperature and has a good shape, color and smell. Method: This study uses action research design. This action research design aims to identify and find solutions to a problem under study. In this study, using 4 cycles between important components, such as planning, action, observation, and reflection. This research planning is in the form of work planning stages that must be carried out at the time of the research, then followed by research and observation of the results of the research then analyzed as a reflection of the researcher's achievements at the time of the research.

Results: The result of drying shrinkage from the simplicia used was betel leaf of $73.4 \%$ based on the $\mathrm{pH}$ stability test, which increased the preparation, homogeneous and lasted for 20 days. Conclusion: the conclusion of this research is Formula II and III can last for 20 days at room temperature storage (15-30oC) with an initial $\mathrm{pH}$ of 4 and a final $\mathrm{pH}$ of 6 , brownish yellow, distinctive smell of lime and betel, slippery texture. At cold temperatures $( \pm 4 o C)$, formulas II and III can last for 21 days.

Keywords: Betel leaf, flaxseed gel, lime juice, antiseptic gel.

\section{PENDAHULUAN}

Pemakaian antiseptik tangan dalam bentuk sediaan gel di kalangan masyarakat menengah keatas sudah menjadi suatu gaya hidup. Beberapa sediaan paten antiseptik tangan dapat dijumpai di pasaran. Cara pemakaiannya adalah dengan diteteskan pada telapak tangan, kemudian diratakan pada permukaan tangan. Respon yang positif terhadap penggunaan antiseptik tangan barangkali berkaitan dengan paradigma bersih itu sehat, serta pemakaiannya yang praktis. Gel antiseptik tangan yang beredar dipasaran mengandung zat antiseptik yang digunakan untuk membunuh kuman yang ada di tangan, yang biasanya terdiri dari alkohol dan triklosan yang merupakan bahan kimia sintetis. Zat ini dapat mencegah multiplikasi organisme pada permukaan tubuh, dengan cara membunuh mikroorganisme tersebut atau menghambat pertumbuhan dan aktivitas metaboliknya, akan tetapi penggunaan berlebih dari alkohol dan antiseptik yang berasal dari bahan kimia sintetis lain dapat menyebabkan kekeringan pada permukaan tangan oleh karenanya perlu dicari sediaan gel antiseptik tangan berbahan dasar alami yang relatif aman, murah serta mudah didapat. Indonesia memiliki tanaman sirih yang beranekaragam, diantaranya adalah sirih hitam, sirih merah, sirih putih, sirih hijau, sirih wulung, sirih perak, sirih gading, sirih irian, sirih hati, dan sirih bulu. Yang paling masyarakat sering gunakan dan menanamnya adalah sirih hijau, karena sirih yang lain tertanam liar di hutan sehingga susah untuk mendapatkannya. Sirih hijau mempunyai kelebihan daya antiseptik yang lebih dominan dibanding sirih lain, karena daya antiseptiknya yang kuat sering dimanfaatkan secara empiris untuk mengobati berbagai penyakit. Kandungan tanaman sirih hijau sebagai antibakteri yaitu adanya flavonoid dan saponin dan tanin. Sirih hijau dan sirih merah tentu berbeda dari segi manfaat dan juga warna daunnya, sirih hijau lebih dimanfaatkan untuk mengobati penyakit ringan atau self medication.[1] Berkembangnya keinginan masyarakat untuk menggunakan bahan alam atau "back to nature", ditanggapi dengan banyak produk-produk topikal berbahan aktif tanaman untuk perawatan kesehatan, kosmetik dan pencegahan penyakit. Piper batle Linn atau sirih hijau merupakan salah satu tanaman yang diketahui berkhasiat sebagai antiseptik. Penggunaan sirih hijau secara tradisional biasanya dengan merebus daun sirih kemudian air rebusan digunakan untuk kumur dan membersihkan bagian tubuh lain, atau daun sirih dilumatkan kemudian ditempelkan pada luka.[2] Diketahui kandungan daun sirih adalah minyak atsiri yang terdiri dari hidroksi kavikol, kavibetol, estargiol, eugenol, metileugenol, karvakol, terpen, sekuiterpen dan tanin. Ekstrak daun 
sirih telah dikembangkan dalam beberapa bentuk sediaan seperti pasta gigi, sabun, obat kumur karena daya antiseptiknya. Sediaan perasan, infus, ekstrak air-alkohol, ekstrak heksan ekstrak kloroform maupun ekstrak etanol dari daun sirih mempunyai aktivitas daya antiseptik.[3] Gel Antiseptik merupakan sediaan yang berbentuk semi padat yang terbuat dari suspensi yang dibuat dari partikel molekul organik kecil hingga besar, terpentrasi oleh suatu cairan. Keuntungan yang di dapat oleh sedian gel adalah mudah merata jika dioleskan pada kulit tanpa penekanan, memberi tekstur dingin, dan mudah untuk digunakan. Gel antiseptik lebih praktis untuk dibuat atau digunakan.[4] Biji rami merupakan biji sumber terbaik asam lemak omega 3 yang mengandung fitokimia dan antioksidan kuat. Biji rami juga salah satu sumber terkaya lignan dan isoflavon. Biji rami adalah sejenis tanaman biji yang salah satu mengandung antioksidan alami dari sumber nabati yang terbaik untuk meningkatkan imunitas tubuh. Selain diolah menjadi bahan makanan biji rami dapat di ekstrak menjadi minyak atau gel.[5] Jeruk nipis merupakan salah satu tanaman penghasil minyak atsiri yang sebagian besar mengandung terpen, siskuiterpen alifatik, turunan hidrokarbon teroksigenasi dan hidrokarbon aromatik (Calvacanti, et al, 2009). Minyak dari ekstrak jeruk nipis dapat digunakan sebagai parfum untuk memancarkan aroma kesegaran. [6]

\section{METODE PENELITIAN}

Penelitian tersebut di Sekolah Tinggi Ilmu Kesehatan Holistik Purwakarta yang berada di Jl. Veteran No. 272, Desa Cisereuh, Kecamatan Purwakarta, Kabupaten Purwakarta. Tempat ini dipilih dengan tersedianya peralatan yang dibutuhkan, dimulai dari pembuatan sediaan hingga pengamatan fisik sediaan gel antiseptik daun sirih hijau (Piper betle linn) dengan basis biji rami (Linum usitatissimum) dan penambahan sari jeruk nipis (Citrus $\mathrm{x}$ aurantiifolia) sebagai aromatik. Penelitian dilaksanakan selama 3 minggu.

\section{HASIL PENELITIAN}

\section{Hasil uji kesukaan}

Tabel 1. Hasil Uji Kesukaan Sediaan Gel Antiseptik

\begin{tabular}{|c|c|c|c|c|}
\hline \multirow{2}{*}{$\begin{array}{l}\text { Jenis } \\
\text { yang } \\
\text { Diuji }\end{array}$} & \multirow[t]{2}{*}{ Skor } & \multicolumn{3}{|c|}{ Kode Sampel } \\
\hline & & FI & FII & FIII \\
\hline \multirow[t]{2}{*}{ Warna } & Suka & 3 & 4 & 4 \\
\hline & $\begin{array}{l}\text { Tidak } \\
\text { Suka }\end{array}$ & 2 & 1 & 1 \\
\hline \multirow[t]{2}{*}{ Aroma } & Suka & 2 & 4 & 2 \\
\hline & $\begin{array}{c}\text { Tidak } \\
\text { Suka }\end{array}$ & 3 & 1 & 3 \\
\hline \multirow[t]{2}{*}{ Bentuk } & Suka & 3 & 2 & 4 \\
\hline & $\begin{array}{c}\text { Tidak } \\
\text { Suka }\end{array}$ & 2 & 3 & 1 \\
\hline \multicolumn{2}{|c|}{ Jumlah } & $\begin{array}{c}\mathrm{S}=8 \\
\mathrm{TS}=7\end{array}$ & $\begin{array}{c}\mathrm{S}= \\
10 \\
\mathrm{TS}= \\
5\end{array}$ & $\begin{array}{l}\mathrm{S}=10 \\
\mathrm{TS}=5\end{array}$ \\
\hline
\end{tabular}




\section{Hasil uji pH dan uji homogenitas}

\begin{tabular}{|c|c|c|c|c|c|c|c|c|c|c|c|c|c|c|c|c|c|c|c|c|c|c|}
\hline $\begin{array}{l}\text { Suhu } \\
\text { Ruan }\end{array}$ & Hari ke- & 1 & 2 & 3 & 4 & 5 & 6 & 7 & 8 & 9 & $\begin{array}{l}\mathbf{1} \\
\mathbf{0}\end{array}$ & $\begin{array}{l}1 \\
1\end{array}$ & $\begin{array}{l}1 \\
2\end{array}$ & $\begin{array}{l}\mathbf{1} \\
\mathbf{3}\end{array}$ & $\begin{array}{l}1 \\
4\end{array}$ & $\begin{array}{l}\mathbf{1} \\
\mathbf{5}\end{array}$ & $\begin{array}{l}1 \\
6\end{array}$ & $\begin{array}{l}1 \\
7\end{array}$ & $\begin{array}{l}1 \\
8\end{array}$ & $\begin{array}{l}1 \\
9\end{array}$ & $\begin{array}{l}\mathbf{2} \\
\mathbf{0}\end{array}$ & $\begin{array}{l}2 \\
1\end{array}$ \\
\hline g & pH & 4 & 4 & 4 & 4 & 4 & 4 & 4 & 5 & 5 & 5 & 5 & 5 & 5 & 5 & 6 & 6 & 6 & 6 & 6 & 6 & 6 \\
\hline & $\begin{array}{l}\text { Homogenita } \\
\text { s }\end{array}$ & & & \multicolumn{19}{|c|}{ Homogen } \\
\hline \multirow{4}{*}{$\begin{array}{c}\text { Suhu } \\
\text { Dingi } \\
\text { n }\end{array}$} & Hari ke- & 1 & 2 & 3 & 4 & 5 & 6 & 7 & 8 & 9 & 1 & 1 & 1 & 1 & 1 & 1 & 1 & 1 & 1 & 1 & 2 & 2 \\
\hline & & & & & & & & & & & 0 & 1 & 2 & 3 & 4 & 5 & 6 & 7 & 8 & 9 & 0 & 1 \\
\hline & pH & 4 & 4 & 4 & 4 & 4 & 4 & 4 & 5 & 5 & 5 & 5 & 5 & 5 & 5 & 6 & 6 & 6 & 6 & 6 & 6 & 6 \\
\hline & $\begin{array}{l}\text { Homogenita } \\
\text { s }\end{array}$ & & & \multicolumn{19}{|c|}{ Homogen } \\
\hline
\end{tabular}

\section{Hasil uji organoleptik}

Hasil pengamatan uji organoleptik pada sediaan gel antiseptik tangan ini menunjukkan bahwa, semua sediaan gel antiseptik daun sirih hijau (Piper betle linn) dengan basis biji rami (Linum usitatissimum) dan penambahan sari jeruk nipis (Citrus $x$ aurantiifolia) sebagai aromatik dengan

Hasil uji organoleptik dari sediaan gel antiseptik tangan selama 3 minggu pada variasi formula berbentuk semi solid dengan tekstur licin sedangkan untuk bau dan warna tergantung dari konsentrasi sari jeruk nipis yang digunakan. Semakin banyak konsentrasi sari jeruk nipis maka warna sediaan gel antiseptik akan semakin pudar serta semakin tajam aroma khas dari sari jeruk nipisnya.

suhu kamar $15-30^{\circ} \mathrm{C}$ dapat dilihat pada Tabel 3, berikut ini:

Tabel 3. Hasil Uji Organoleptis

\begin{tabular}{|c|c|c|c|}
\hline Formula & $\begin{array}{c}\text { Pengamatan } \\
\text { Minggu ke- }\end{array}$ & $\begin{array}{c}1 \\
(0-7 \text { Hari })\end{array}$ & $\begin{array}{c}2 \\
(8-14)\end{array}$ \\
\hline \multirow{4}{*}{ I } & Warna & Kuning pucat & Kuning pucat \\
\cline { 2 - 4 } & Bau & Sedikit wangi jeruk+sirih & Sedikit wangi jeruk+sirih \\
\cline { 2 - 4 } & Bentuk & Semi solid & Semi solid \\
\cline { 2 - 4 } & Rasa & Licin & Licin \\
\hline \multirow{4}{*}{ II } & Warna & Kuning Pucat & Kuning Pucat \\
\cline { 2 - 4 } & Bau & Khas Jeruk + Sirih & Semi Solid \\
\cline { 2 - 4 } & Bentuk & Semi Solid & Licin \\
\cline { 2 - 4 } & Rasa & Licin & Kuning Pucat \\
\hline \multirow{3}{*}{ III } & Warna & Kuning Pucat & Semi Solid \\
\cline { 2 - 4 } & Bau & Semi Solid & Licin \\
\cline { 2 - 4 } & Bentuk & Licin & Khas Jeruk + Sirih \\
\cline { 2 - 4 } & Rasa & & \\
\cline { 2 - 4 } & & &
\end{tabular}

Tabel 3, menunjukkan bahwa formula I ini pada minggu ke-3 tepatnya hari ke-15 mulai terjadi perubahan bau karena timbulnya bau tengik yang bercampur dengan wangi khas daun jeruk dan berjamur berwarna hitam. Untuk formula II pada hari ke-17 mulai berbau tengik juga, semakin lama pengamatan bau tengiknya semakin tajam. Formula III mulai terjadi perubahan bau dihari ke-14, bau khas dari jeruk yang tajam bercampur dengan bau tengik dan sedikit ditumbuhi bercak putih.
Sediaan gel antiseptik dengan penyimpanan di suhu dingin $\pm 4^{\circ} \mathrm{C}$ relatif stabil dibandingkan dengan sdiaan gel antiseptik tangan yang disimpan disuhu kamar $15-30^{\circ} \mathrm{C}$. Berikut beberapa tabel hasil pengamatan uji organoleptik dari sediaan gel anti septik. Selama pengamatan berlangsung, setelah beberapa hari terjadi perubahan bentuk menjadi mencair pada sediaan gel antiseptik yang disimpan pada suhu kamar $15-30^{\circ} \mathrm{C}$, dan pada sediaan gel antiseptik yang disimpan pada suhu $\pm 4^{\circ} \mathrm{C}$ mengerut. 
Tumbuhnya jamur pada sediaan gel antiseptik tangan ini khususnya pada sediaan yang disimpan di suhu kamar 15$30^{\circ} \mathrm{C}$ disebabkan oleh sifat jamur yang mesofilik atau dapat tumbuh dengan baik di suhu kamar $15-30^{\circ} \mathrm{C}$. Selain itu jamur juga dapat tumbuh pada media yang memiliki $\mathrm{pH}$

\section{Hasil susut pengeringan}

Tabel 4. Hasil Susut Pengeringan Simplisia Daun Sirih (Pipper bettle L.)

\section{PEMBAHASAN}

\section{Uji Kesukaan}

Hasil uji kesukaan untuk sediaan gel antiseptik tangan ini didapat formula II yang paling banyak diminati, dapat dilihat pada Tabel 4.2 yang menunjukkan bahwa baik warna, aroma, dan bentuk formula II dan III paling tinggi perolehan nilainya.

Menurut Responden 1, formula II dan III memiliki warna yang tidak terlalu pekat, terlihat jernih, dan memiliki aroma khas daun sirih dan jeruk nipis, bentuk dari sediaan gel antiseptik tidak terlalu kental.

Menurut Respinden 2, Sediaan gel antiseptik dengan formula II paling baik dari segi aromanya dan bentuk teksturnya, karena aroma yang dihasilkan tidak terlalu menyengat. Bentuk dan teksturnya juga baik, sediaan kental seperti gel meski sedikit cair.

Menurut Responden 3, Sediaan gel antiseptik formula II dan III ini memiliki warna yang tidak terlalu pekat dan sedikit jernih. Bentuk dari sediaan gel ini kental meski sedikit cair namun tekstur gelnya sangat baik.

Menurut Responden 4, Sediaan gel antiseptik ini pada semua formula saat diteteskan pada telapak tangan lalu diusap agak sedikit lengket tetapi setelah didiamkan beberapa detik lengketnya hilang dan menjadi lembut serta tidak kasar pada telapak tangan.

Menurut Responden 5, sediaan gel antiseptik pada formula III sangat tajam aroma jeruk nipisnya sehingga bau dari sirihnya hanya sedikit dan teksturnya tidak terlalu gel tapi agak sedikit mencair sehingga saat di oleskan pada telapak tangan mudah menyebar dan meresap. dibawah 7. Jamur sendiri memerlukan air, sumber energi, sumber nitrogen, dan vitamin untuk pertumbuhan dan metabolismenya, memungkinkan jamur dapat tumbuh pada sediaan gel antiseptik ini dalam penyimpanan yang lama di suhu kamar $15-30^{\circ} \mathrm{C}$.

\section{Uji pH}

Pengukuran $\mathrm{pH}$ sediaan gel antiseptik ini menggunakan alat $\mathrm{pH}$ stick yang dilakukan selama penelitian berlangsung dapat dilihat pada Tabel 4.3 untuk sediaan gel antiseptik yang disimpan pada suhu kamar $15-30^{\circ} \mathrm{C}$ dan sediaan gel antiseptik tangan yang disimpan pada suhu dingin $\pm 4^{\circ} \mathrm{C}$.

Sediaan gel antiseptik tangan rata rata pada minggu pertama berkisar pada angka 4, sedangkan pada minggu ke-2 dan ke-3 mulai terjadi kenaikan angka $\mathrm{pH}$ menjadi 5, selanjutnya di minggu ke-3 pH naik angka lagi menjadi 6.

Tabel 2 menunjukan bahwa sediaan gel antiseptik daun sirih hijau (Piper betle linn) dengan basis biji rami (Linum usitatissimum) dan penambahan sari jeruk nipis (Citrus $x$ aurantiifolia) sebagai aromatik memenuhi persyaratan untuk $\mathrm{pH}$ kulit, yaitu berada rentang 4.5-6.5. Kenaikan pH pada sediaan gel antiseptik tangan ini disebabkan oleh beberapa faktor, seperti faktor lingkungan diantaranya suhu dan penyimpanan yang kurang baik.

\section{SIMPULAN}

Berdasarkan penelitian yang telah dilakukan, maka dapat disimpulkan bahwa sediaan sediaan gel antiseptik daun sirih hijau (Piper betle linn) dengan basis biji rami (Linum usitatissimum) dan penambahan sari jeruk nipis (Citrus $x$ aurantiifolia) sebagai aromatik dibuat dalam tiga formulasi dimana simplisia daun sirih yang digunakan telah memenuhi persyaratan mutu kadar air, yaitu $\leq 10 \%$. 
Pengamatan stabilitas fisik dilakukan pada suhu kamar $15-30^{\circ} \mathrm{C}$ dan $\pm 4^{\circ} \mathrm{C}$ dengan formula sediaan gel antiseptik yang berbeda, dan menghasilkan formula II dan III yang paling disukai oleh responden dibandingkan dengan formula I. Hal ini dilihat dari hasil uji organoleptik sediaan gel yang mana formula II dan III dengan kadar $10 \mathrm{ml}$ infusa daun sirih , $10 \mathrm{ml}$ gel biji rami dan $10 \mathrm{ml}$ sari jeruk nipis untuk formula II dan $15 \mathrm{ml}$ untuk formula III yang paling lama ditumbuhi jamur pada suhu kamar $15-30^{\circ} \mathrm{C}$ dan hasil uji kesukaan dimana dari 20 responden yang menilai menyukai penampilan sediaan gel antiseptik dengan formula II dan III.

Formula II dan III dapat bertahan selama 20 hari pada penyimpanan suhu kamar $\left(15-30^{\circ} \mathrm{C}\right)$ dengan $\mathrm{pH}$ awal 4 dan $\mathrm{pH}$ akhir 6, kuning kecoklatan, bau khas jeruk nipis dan sirih, tekstur licin. Pada suhu dingin $\left( \pm 4^{\circ} \mathrm{C}\right)$, formula II dan III dapat bertahan selama 21 hari.

\section{DAFTAR PUSTAKA}

1. Fuadi S. Efektivitas ekstrak daun sirih hijau (Piper betle L) terhadap pertumbuhan bakteri stretococcus pyogenes in vitro [skripsi]. Jakarta : Universitas Islam Negeri Syarif Hidayatullah; 2014.

2. Lindawaty, A. 2009. Identifikasi Antioksidan Hasil Isolasi dari Daun Sirih. Skripsi. Fakultas pertanian Unila. Bandar Lampung. Hal; 6-8.

3. Khustian F, 2013. Pengaruh Cara Pengolahan dan Jumlah Daun Sirih Terhadap Pertumbuhan Porphyromonas gingivalis (Kajian in vitro). Universitas Gajah Mada [skripsi].

4. Rahman, m.A. 2012. Kitosan sebagai bahan antibakteri alternatif dalam formulasi gel pembersih tangan (Hand Sanitizer). Bogor. Institut Pertanian Bogor. Skripsi.

5. Lusiana, A., Sumarni, S, \& Ayuningtyas, A. (2017). Efektivitas biji rami sebagai sumber lignan. JURNAL KESEHATAN INDRA HUSADA, 5(1), 23-31.

6. Haryanto, Sri, 2006 . Sehat dan Bugar secara alami dengan manfaat dari jeruk nipis. Jakarta : Penebar Plus. Hal 60. 